\title{
Halfway there - The evolution of local alcohol control in California. Part I: The system as it has developed
}

\author{
Friedner D. Wittman ${ }^{1,2}$ \\ ${ }^{1}$ CLEW Associates, Berkeley, California, United States \\ ${ }^{2}$ Alcohol Research Group, Public Health Institute, Emeryville, California, United States
}

\begin{abstract}
Local control over retail alcohol sales in California cities provides substantial capacity to reduce and prevent alcohol-related harm. This paper shows how local control works in California to prevent harm at retail alcohol outlets. Prior to issuing a retail license to an outlet operator, the state Alcoholic Beverage Control Department (ABC) waits until the local jurisdiction (city or county) issues a land-use permit (also called a zoning permit or use permit). Localities have discretionary authority to impose preventive "conditions" on the use permit to protect public health and safety by imposing restrictions on setting design, operation, and hours of operation for the retail alcohol outlet. Within the state/local control system, city options include Level 1 permissive zoning (no restrictions), Level 2 problem-solving zoning (restrictions on new/expanded outlets), and Level 3 community oversight (restrictions on existing and new outlets). Since 1980 the scope of local control has progressed from nil (Level 1 permissive zoning) to Level 3 preventive surveillance for all outlets. Higher-level zoning requires local politics in which the $\mathrm{ABC}$ is not involved. A companion article (Wittman, 2016) describes the evolution of local control for retail alcohol availability in California’s local jurisdictions from 1980 to 2015.
\end{abstract}

\section{Introduction}

As elsewhere in the United States, control of the conditions of alcohol availability was made in the first instance a state responsibility when national Prohibition was repealed in 1933. Unlike many other U.S. states, control of the alcohol market was kept at the state level, with little input from local government. As a 1981 analysis put it, "local governments in California have played only a minimal role in determining the nature of the distribution system because the state has maintained preemptive control over the alcohol trade" (Bunce et al., 1981, p. 161). This arrangement was favored by alcohol industry interests, since local control and local option concerning alcohol sales had long been a temperance movement concern and rallying cry.

Though state control was initially in the hands of a general state fiscal agency, in the mid-1950s scandals in the state legislature led to the current arrangement whereby state regulation of the alcoholic beverage industry is overseen by the Alcoholic Beverage Control Department (ABC), which reports directly to the state governor. Reform legislation in the mid-1950s provided great flexibility for participation by local jurisdictions (e.g., cities, counties, special districts) in the retail outlet licensing process by applying their land-use planning and zoning authority. Currently the ABC issues a retail license only after the city or county, exercising this authority, approves a use permit to exercise the privileges of the ABC license at a specific address in a specific type of setting. Both state and local law enforcement agencies carry out enforcement duties. This two-level division of labor oversees approximately 45,000 on-sale and 29,000 off-sale retail licenses operating in nearly 500 cities in 58 counties.

The following discussion outlines the emergence of local government influence on the marketing and availability of alcohol after the creation of the California ABC in the 1950s. The process has been incremental and arguably incomplete, and it has primarily been accomplished through court decisions and local ordinances, rather than legislative actions at the state level.

\section{How Local Control Works in California: State and Local Powers}

The California ABC Code (S. 23790) explicitly recognizes the authority of California cities and counties to use local land-use zoning ordinances to control the "mode and manner" of alcohol sales. In practical terms this means local authority to limit the number of retail alcohol outlets in the city along with their location, design, hours, and conditions of operation. California has two levels of government below the state level: counties and cities. The 
state is divided into 58 counties. There are 482 incorporated cities and towns in California, but much of the state is outside these municipalities; in those areas the counties exercise powers otherwise assigned to municipalities, including zoning and land-use powers. As things stand, the state allows local jurisdictions full discretion in the use of their local powers; the choice is left to each city council or county board of supervisors to make greater or lesser use of land-use permits for retail alcohol outlets. Cities and counties have identical land-use powers and operate independently of each other with respect to the ABC. Each jurisdiction has its own elected legislative body (a city council or county board of supervisors) and administers its zoning ordinances primarily through the planning department and the police department. Cities are far more active than counties regarding local control for retail alcohol outlets; this article focuses on city (municipal) experience, although theoretically the discussion applies equally to both jurisdictions.

How local control works in cities and counties: Use permits. All U.S. cities and counties use local ordinances to regulate land-use according to a local master plan that designates geographic "zones” for various types of land-use types (e.g., commercial, residential, industrial, public) containing certain settings (e.g., certain types of stores, types of housing, types of manufacturing facility, various public uses). Land-use zones are divided into blocks separated by streets; the blocks are divided into parcels (properties), each with a street address. Use permits are issued by the local zoning authority for the setting at the street address.
In current California practice three forms of permit are issued: (1) Automatically for uses that meet published requirements published in the zoning ordinance and landuse plan (Level 1 zoning in this paper); (2) Conditionally following case-by-case review by city staff or a zoning board or commission (Level 2 zoning); and (3) On a mandatory basis requiring certain features of design and operation for each outlet (Level 3 zoning). Permit applications may also be denied for certain reasons: Nonconformance with zoning laws or city development plans; protection of public health and safety (reduction of harm); and preservation of social and economic well-being (quality of life) in the public interest.

Level 2 and Level 3 zoning ordinances specify certain design features and operational requirements known as "conditions" that limit the activities of retail alcohol outlets appropriate to the basic land-use purposes of the zoned area. These conditions become part of the outlet's use permit (often called a conditional use permit or CUP) in several categories described further below. Failure to comply with these conditions can result in revocation of the CUP. Revocation will put the establishment out of business.

Local control powers are discretionary, as summarized in Figure 1. Explaining how cities apply their zoning powers for retail alcohol outlets is best done by reviewing the way cities move forward from relying on the lowest "permitted use" category, a default starting point required by the state, to adoption of Deemed Approved Ordinances, in which the city imposes substantial regulation of the use permit specifically to protect public health and safety.

\section{Figure 1}

California state and local authority to regulate retail alcohol outlets

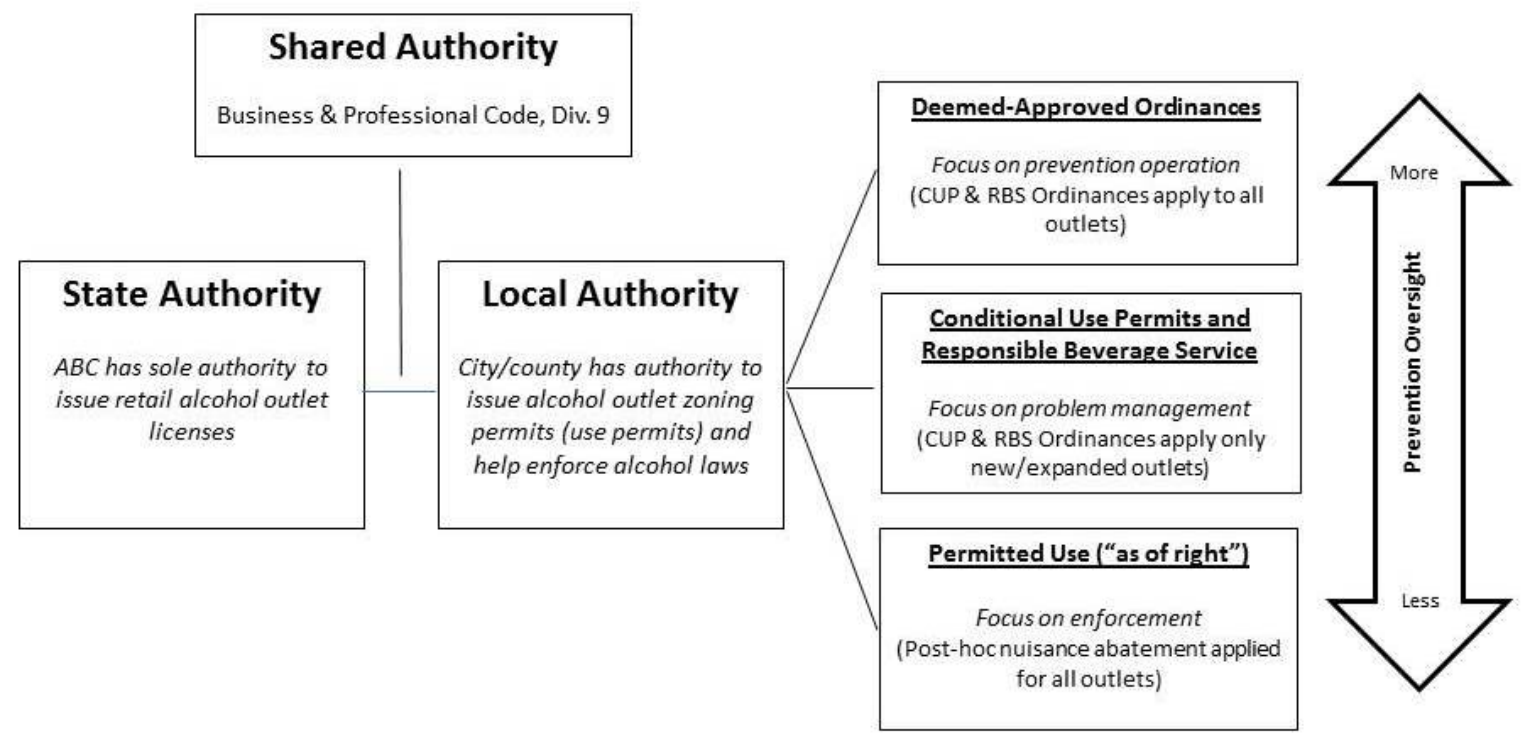

Legend: CUP=Conditonal Use Permit; RBS=Responsible Beverage Service; ABC=Alcoholic Beverage Control Department 
Development of local alcohol control through land-use planning powers. Use of this three-level structure for zoning approaches to local control of the alcohol market began in California starting in 1980 . We now turn to a discussion of this historical development.

Local authority to protect public health and safety. Several landmark U.S. Supreme Court decisions opened the way, starting in 1926, for all cities and counties to use local zoning laws to restrict private uses of property specifically for the public purpose of protecting public health, safety, and welfare. These rulings permit local jurisdictions to regulate private land-use for public benefit without having to compensate the property owner (Euclid v. Ambler), provided the public agency can show a "nexus" establishing a credible connection between regulation of the land-use and reductions in harms attributable to the land-use (Nectow v. Cambridge), and provided the proposed controls are "proportional" for the protections provided (reasonably effective and not ruinously expensive for private owner) (Dolan v. Tigard). According to these rulings the nexus must be reasonable-that is, credible (rational) with some predictive value. The reasonable and reliable connection may be either correlational or causal.

Liberal zoning policies for commercial land-uses. California cities have a long history of liberality in favor of zoning for local businesses, including retail alcohol outlets. Before 1980, most local officials routinely viewed their roles regarding alcohol outlets as adjunct to state control (e.g., help with law enforcement after the ABC has issued a license) and did not especially restrict the location, number, design, and operation of retail alcohol outlets compared to other retail commercial land-uses. Local officials usually counted on the ABC licensing process to provide oversight for design and operation of the establishment.

Following reform of the ABC in the mid-1950s, California localities continued to take a liberal business-friendly perspective toward land-use regulations for retail alcohol outlets. Local officials applied a "laissez faire" approach to zoning for businesses generally, treating alcohol outlets the same as other types of commercial outlet. This approach views the operator as a competent, law-abiding business person who does not need close supervision from the city or county. This approach assumes problems with retail outlets will be confined to a few troublesome operators (California officials sometimes call them "bad actors" or "bad apples") and not to the retail outlet per se. Officials at both state and local levels treated problematic outlets as behavioral problems for state ABC sanctions and local law enforcement, not as land-use issues. These officials routinely deferred to the state $A B C$ both to regulate the licensee's sale of alcohol and to oversee the retail alcohol outlet premises (place of business).

In fact, as will be described further below, the place where alcohol is sold, the total number of outlets and the density (geo-graphic concentration) of outlets do contribute to problems at retail alcohol establishments in a given city or county. While most retail alcohol outlet operators are indeed competent and law-abiding, the laissez-faire perspective does not account for health and safety problems attributable to retail alcohol outlets, which sell a potent psychoactive drug in the aggregate at the community or district level. The problems attributable to community contexts, to setting type, and to physical design features are due to factors other than operator competence. Nor does the laissez-faire view challenge questionable sales practices based on community norms and conduct shared by retail outlet operators who are also members of the community ("it's what my customers want") as well as businesspeople. California's local retail alcohol outlet community has no internal mechanism among its members to assure high fidelity to safe and acceptable serving practices for all establishments (Hanour, 2013). These concerns are a job for local zoning.

Levels of zoning for retail alcohol outlets. Historically, California cities and counties move to higher levels of zoning oversight on a reactive basis after finding that default "laissez-faire" through first-level zoning does not work for retail alcohol outlets. When this assumption breaks down, localities develop more stringent zoning requirements on a post-hoc problem-solving basis. Action is taken to stem the obvious flow of continuing problems associated with retail outlets by moving to a second level of CUP zoning. This occurs after it has become clear that the outlet-related problems are not being adequately controlled by the state ABC nor by heightened local law enforcement. Should problems persist at the second level, the local jurisdiction moves to a third level of deemed-approved ordinance (DAO) zoning when it is clear that problemsolving CUP zoning is not adequate and greater general, preventive oversight is necessary. Discussion below summarizes movement through these three levels.

Level 1 - Permissive zoning (regular use permits or "laissez-faire" zoning). The regular use permit (also called a zoning permit, or simply a use permit) regulates retail alcohol outlets on a physical basis by imposing physical standards published in the land-use plan and zoning ordinance. These standards include items pertaining to physical design, height limits, setback, and lot-coverage limits, and building/life-safety code requirements appropriate for the commercial outlets in that zone. Regular use permits are granted automatically to permit requests that meet the published standards. This approval is called "on demand" or "as of right" approval without further discretionary review by the city. Level 1 zoning treats retail alcohol outlets the same as other commercial businesses such as clothing stores, laundromats, or hardware stores. No special regulations for operation or behavior on the premises are included. Alcohol outlet operators are presumed to know how to operate their businesses safely and appropriately, and they are expected to self-supervise their observance of state $A B C$ license requirements not to sell to underaged persons or to people who are obviously intoxicated.

Implementation: Laissez-faire zoning for retail alcohol outlets was standard practice in California cities until the late 1970s, when a rising tide of outlet-related problems forced cities to higher levels of zoning. Today, even with 
higher levels of zoning, most retail outlets in a given city continue to operate on a self-supervised basis with few visible problems. City monitoring to assure compliance is limited to post-hoc law enforcement and nuisance abatement. Troublesome outlets are treated as infractions and crimes and violations of $\mathrm{ABC}$ law-that is, as behavioral problems with the licensee. For serious continuing problems, the city attorney proceeds with nuisance abatement proceedings directed toward the licensee and/or the owner of the premises. Nuisance abatement is expensive and time-consuming, and it often involves the court system. Nuisances are typically "abated" or "mitigated" via negotiated compromises at the zoning board. The results often reduce problems without eliminating them. Revocation procedures are used as a last resort, and only after a lengthy process is a use permit revoked.

Level 2 - Problem-solving zoning (CUPs). CUPs are conditions imposed by the zoning authority for safe design and operation of the retail alcohol outlet. CUPs apply to new alcohol outlets and to substantial expansion of existing outlets. Cities write CUPs after local experience with outlet-related problems accumulates beyond a tolerable level; that is, after Level 1 zoning has permitted problemoutlets to operate, and ABC sanctions and local law enforcement prove inadequate. CUPs place restrictions on the outlet in the following categories: (i) Location (e.g., land-use areas or zones where the outlet is permitted); (ii) $\mathrm{ABC}$ license type and type of land-use setting (e.g., type of store or restaurant); (iii) design of the building (e.g., size, floor layout, signage and appearance, furnishings); (iv) density and adjacency (e.g., concentration of outlets in relation to each other [bunching], proximity to sensitive uses); (v) operational features (e.g., noise limits, hours of operation, signage and advertising displays, parking requirements); and (vi) training and management standards for sale/service of alcoholic beverages (e.g., responsible beverage service [RBS] practices and policies) (Saetta \& Mosher, 2014).

CUPs are written to slow increases in growth of numbers and types of alcohol outlets that create increasing neighborhood and police problems, particularly in compact geographic areas that experience high geographic density or "bunching" of alcohol outlets. CUPs are also written to constrain certain types of outlets (for example, late-night full-service on-sales establishments) that become a focus for problems requiring greater control and enforcement. Requirements may be imposed on the "mode or manner" for sale of alcoholic beverages that restrict container size, alcohol content, and number of containers. These requirements may include adoption of RBS practices recognized by the state $\mathrm{ABC}$ or an equivalent authority. In addition to training requirements for staff and management practices for owner/managers, RBS-related CUP conditions may place preventive limits on design and operation of the establishment (called “operating standards") (Hanour, 2013; Rogers et al., 2014).

Implementation. Over the last 40 years, California cities have steadily increased their use of Level 2 conditions on retail alcohol outlets specifically to protect health and safety and to protect social well-being. Use of CUP zoning expanded rapidly through the 1980s and 1990s to stem the flow of visible problems associated with increasing numbers of alcohol outlets. Alcohol outlet CUP ordinances functioned effectively for this purpose and cities continue to develop them at this writing. An estimated four out of five California cities currently apply CUP ordinances to retail alcohol outlets.

The CUP zoning approval process is considerably more demanding than over-the-counter approvals for regular use permits issued under Level 1 zoning. Scrutiny includes a public review process in which neighbors, police, and other interested parties have the opportunity to raise concerns about health and safety concerns for the new or expanded outlet. The CUP review process takes time and money, and it results in conditions that constrain risky outlet operations. The process also includes considerable uncertainty, since the application could be denied for reasons beyond the operator's control in addition to concerns about operator behavior. Under these circumstances, exploitative and opportunistic operators are less likely to apply for an alcohol outlet permit than under Level 1 zoning.

CUPs start working immediately to abate problems but the local CUP oversight process typically works slowly through business turnover of premises with problems and increasing rates of retailer compliance with CUP conditions. It usually takes a year or two to reduce the flow of problems substantially and to see improvements in outlet operations. Most communities experience steady progress in the reduction of trouble with outlets as long as the CUP review process is diligently applied.

With respect to enforcement, outlets in violation of CUP conditions are accountable primarily to the local zoning board rather than the city attorney's office. Zoning boards have greater leeway to mitigate problems by negotiating precise and accountable compliance to the relevant CUP conditions, backed by the threat of permit revocation for failure to comply. This approach obtains precise results relatively quickly, bypassing the drawn-out procedures of the city attorney's office and the labyrinthine ABC enforcement system. At first, troublesome "grandfathered" outlets operating under pre-existing Level 1 laissez-faire use permits without conditions were technically exempt from more recent CUP requirements. Problems with a grandfathered outlet were still handled through the cumbersome law enforcement and nuisance abatement methods described in Level 1 . This problem was resolved by Level 3 DAO zoning.

Level 3 - Community oversight zoning (DAOs). DAOs provide a way to apply current CUP conditions to regulate nuisances at problematic "grandfathered" use permits issued prior to the passage of a CUP ordinance (Mosher, Cannon, \& Treffers, 2009). Until the early 1990s, existing grandfathered outlets were generally considered exempt from CUP requirements enacted after the outlet's use permit had been issued. This exemption was successfully challenged by community activists in the mid-1990s 
following a massive community disturbance in South Central Los Angeles that put about 200 off-sales outlets out of operation. Initial responses by the City of Los Angeles led to actions that resulted in the state Supreme Court affirming the city's powers to regulate nuisances at all retail alcohol outlets (Bass, 1999). These findings were followed by a campaign to create a general requirement in the City of Oakland's zoning ordinances that all alcohol outlets are "deemed approved" to operate free of nuisances; any outlet found to be creating a nuisance can be subject to performance standards (contained in CUP operating conditions) to abate the nuisance (Berkeley Media Studies Group, 1997). The Oakland ordinance opened the way to create a level playing field for application of the city's current alcohol outlet CUP requirements for abating nuisances at all problematic retail outlets currently operating under a state $\mathrm{ABC}$ license.

Implementation. By 2009, 19 cities were identified that had passed DAO ordinances, 12 of which have been analyzed (Mosher, Cannon \& Treffers, 2009). (In 2015, anecdotal information suggests the number of DAO ordinances is growing slowly but steadily and that implementation at this writing is in a developmental stage. California cities are passing DAO ordinances for several types of troublesome grandfathered outlets operating as a nuisance compared to other outlets-for example, those that generate a high frequency of police events. The Court's decisions have been applied to cover all late-night on-sales outlets (Wittman, 2012) and to cover all off-sale outlets in high-crime areas (Kendrick, 2016). These rulings suggest further expansion of DAOs to cover both on-sale and off-sale outlets in a city where nearby residences are highly sensitive to issues with alcohol outlets imbedded in a neighborhood infrastructure that combines residential, commercial, and public spaces such as public parks and grade schools.

DAO ordinances extend a city's zoning oversight to cover both current and future alcohol outlets. This makes it possible for cities to introduce research findings on harm reduction into the local zoning ordinance use-permit process, as the research becomes available, in ways that fairly and effectively update CUP requirements for all existing outlets. As capacity increases to demonstrate a harmful nexus, cities can step up their levels of preventive oversight through model and preventive zoning.

Model zoning and preventive zoning. Local zoning for retail alcohol outlets involves critical issues affecting public health, safety, and neighborhood quality of life. Cities are interested in preventive model ordinances that effectively address problems they all share, and that they can all learn from (Wittman, 1986).

Model zoning ordinances for retail alcohol outlets. Although hundreds of Level 2 and Level 3 ordinances have been written as California cities established preventive local control, there has been little quality control or comparative analysis among ordinances. California cities generally want to be "Number Two"-first in line to adopt a new strategy or technique after another city has worked out all the bugs. Over the years a number of model ordinances have been written for alcohol outlet CUPs that focus on specific conditions for use permits designed to limit high-risk patron behaviors and management practices (Wittman, 1994). The latest version is comprehensive in its coverage and well grounded in legal precedents (Saetta \& Mosher, 2014).

Preventive zoning for high-risk Alcohol and Other Drug (AOD) settings. The advent of DAO zoning offers the prospect of establishing fair and effective public oversight at the community level for all retail outlets on a preventive basis. This oversight system includes establishment of community standards for preventive alcohol management practices by retail alcohol outlet operators and a community-level surveillance system to monitor outlet performance. Systematic reviews of public health and safety research have identified ways in which retail alcohol outlet densities (e.g., land-use and population based) and setting-related variables (e.g., physical design and related management practices) pose risks to public health and safety (Campbell et al., 2009; Babor et al., 2010). The findings support classification of retail alcohol outlets as a land-use category that poses elevated risks to public health and safety. This classification makes retail alcohol outlets eligible for city oversight systems especially designed to monitor high-risk settings both for the individual outlet and for aggregates of outlets by license or setting type and by location. Several local information systems currently provide preventive surveillance of the community environment to monitor health and safety risks in other areas (e.g., the water supply, toxic materials such as lead paint, and leaking gas tanks). Local preventive surveillance systems can also use police event data for routine monitoring of retail alcohol outlet performance through planning and zoning ordinances (Wittman, 2009; Wittman, 2012).

\section{Discussion: Development of preventive local control in California cities}

The advent of DAO zoning invited a sea change in thinking about municipal local control for retail alcohol outlets. Over the last 35 years, cities have progressed from laissezfaire zoning toward preventive, public management zoning for retail alcohol outlets. This progression involves two major shifts in local public policy toward retail alcohol outlets, reflecting a shift in thinking about policy for community-level prevention of AOD-related problems in general within the California AOD prevention field.

First, the local jurisdiction (city or county government) is becoming an increasingly capable resource for specifying local land-use controls specifically to reduce harms and public safety problems associated with retail alcohol availability. Level 3 zoning provides a land-use vehicle for establishing a fence of good practice within which on-sales and off-sales outlets can operate safely and, as recently exemplified in the city of El Cajon (Kendrick, 2016), can resolve long-standing problems that defy the $\mathrm{ABC}$ and 
local law enforcement. Further, cities now have a model for action that applies CUP/DAO use-permit review processes to hold the owner/operator responsible for adopting safe practices for the sale of alcoholic beverages. This model applies both to the individual outlet and for aggregates of outlets by type and in high-risk geographic areas. Local agencies are now able to hold both the server and the drinker responsible for conduct that generates excessive drinking and its sequelae in community problems.

Second, these growing capabilities raise the prospects that cities (that is, concerned community groups working with responsive local officials) can establish firm community standards and set performance levels to manage ways private operators sell alcoholic beverages in response to health and safety issues. Local zoning for alcohol outlets is positioned to move beyond reactive problem-solving to proactive management that protects health and safety. This means establishing performance standards for design and operation of settings where alcohol is sold and consumed in a given community. This raises the prospect that cities will be major partners, along with $\mathrm{ABC}$ and other state agencies, for engaging the retail alcohol outlet community. California cities are emerging as premier sites for balancing public health and safety concerns against private commerce and self-regulation, adding weight on the health and safety side.

California cities do not act alone to develop preventive local controls for retail alcohol availability. Development has occurred in a context of robust support from two state agencies and the California AOD prevention community (i.e., service providers, officials, policy advocates, and researchers). To understand these contributions it will be helpful to trace the evolution of local control for retail alcohol availability from 1980 to the present. A separate paper on this topic is available in Wittman (2016).

\section{Conclusion}

California zoning law is a potent resource for reducing harms associated with retail alcohol availability. Over the last 35 years, cities have increasingly used their zoning authority to apply local control to retail alcohol outlets specifically to reduce harms associated with the outlets. Many cities have applied Level 2 CUP zoning effectively for retail alcohol outlets. However, many problems are still associated with retail establishments, and the preventive potentials of Level 3 DAO zoning are not being widely realized. Assertive support from the state has plateaued since 2005. Now it is time to resume the former levels of support to take full advantage of the growing preventive powers of local control. Wittman (2016) reviews this evolution and comments on a way forward given the current situation.

\section{References}

Babor, T., Caetano, R., Casswell, S., Edwards, G., Giesbrecht, N., Graham K., . . . Rossow, I. (2010).
Alcohol: No common commodity: Research and public policy (2nd ed.). Oxford, England: Oxford University Press.

Bass, K. (1999). Appendix E: The campaign to rebuild South Central Los Angeles without liquor stores. In P. L. Grover (Ed.), Preventing problems related to alcohol availability: Environmental approaches, Reference guide (DHHS Publication No. SMH 993298) (pp. 151-156). Washington, DC, United States: Government Printing Office.

Berkeley Media Studies Group. (1997, December 1). Oakland shows the way. Berkeley Media Studies Group, Issue 3.

Bunce, R., Cameron, T., Collins, G., Morgan, P., Mosher, J., \& Room, R. (1981). California's alcohol experience: Stable patterns and shifting responses. In E. Single, P. Morgan, \& J. de Lint (Eds.), Alcohol, society and the state: II. The social history of alcohol control experiences in seven countries (pp. 159-197). Toronto, Canada: Addiction Research Foundation.

Campbell, C. A., Hahn, R. A., Elder, R., Brewer, R., Chattopadhyay, S., Fielding, J., . . Middleton, J. C. (2009). The effectiveness of limiting alcohol outlet density as a means for reducing excessive alcohol consumption and alcohol-related harms (A guide to community prevention services). American Journal of Preventive Medicine, 37(6), 556-569.

Dolan v. Tigard - Dolan v. City of Tigard, 512 U.S. 687 (1994)

Euclid v. Ambler - Village of Euclid v. Ambler Reality Co, 272 U.S. 365 (1926)

Hanour, G. A. (2013). Business approach to reducing drunk driving. Retrieved from http://www.amazon. com/Business-Approach-Reducing-Drunk-Driving/

Kendrick, G. (2016) Powerful Local Control Remedy Addresses El Cajon's Alcohol Nuisance Problems, Western City Magazine, May, 2016.

Mosher, J. F., Cannon, C., \& Treffers, R. (2009). Reducing community alcohol problems associated with alcohol sales: The case of deemed approved ordinances in California. Felton, CA, United States: Ventura County Health Department Alcohol \& Drug Programs, PreventionServices.

Nectow v. Cambridge - Nectow v. City of Cambridge, 277 U.S. 183 (1928)

Rogers, P., Griffin, M., Kendrick, K., Bloch, S., Hanour, G., \& Wittman, F. (2014, August 11-13). Responsible Beverage Service training as a community prevention resource. Presented at the Substance Use Disorders Statewide Conference, California Department of Community Health Services, Costa Mesa, CA, United States.

Saetta, S. L., \& Mosher, J. F. (2014). Best practices in municipal regulation to reduce alcohol-related harms from licensed alcohol outlets. Ventura County, CA, United States: Ventura County Health Care Agency, Alcohol and Drug Programs.

Wittman, F. D. (1986, November). Issues in controlling alcohol availability. Western City Magazine, 9-13.

Wittman, F. D. (1994, July 8). Development and use of conditional use permits to prevent problems related to retail alcohol outlets: An overview. Presented for the 
workshop, Effective use of local land use controls to prevent problems related to alcohol outlets, Watsonville, CA, United States.

Wittman, F. D. (2009). Lessons for three Orange County cities: Municipal responses to rapid growth of problems at on-sale alcohol outlets. Presentation to California Prevention Collaborative Annual Meeting, Orange County, CA, United States.

Wittman, F. D. (2012, October). Restaurants that "morph" into bars and nightclubs in California communities: What's the problem and what can be done about it? Policy brief for the Community Prevention Initiative. Retrieved from http://www.ca-cpi.org/resources/ search_resources.php?specify_keyword=policy+brief

Wittman, F. D. (2016). Halfway there - the evolution of local alcohol control in California: Part II. Stages and factors in development, 1980-2015. International Journal of Alcohol and Drug Research, 5(3), 109-116. 